\title{
The "Four Principles" and Its Practice of Talent Cultivating in Cross- Border E-commerce
}

\author{
Mei-yu FANG
}

\author{
Zhejiang International Studies University, Hangzhou, China
}

Keywords: Cross border e-commerce, Talent cultivating, Talent cultivating mode, Practice.

\begin{abstract}
There is a serious gap in cross-border e-commerce personnel. In fact, there are many related international trade and e-commerce major in Chinese universities, but the college students who have been recruited can't finish the tasks from their enterprise as required. The training of university cannot be trusted by enterprises, which proves that there are problems in cross-border e-commerce education in universities. This paper analyzes the current situation and problems of cross-border talent training in Chinese universities. Put forward that the talents training of cross border e-commerce in Colleges and universities should start with training plan design, guided by "four principles", namely, stratified segmentation, interdisciplinary, cooperation of government enterprises in Colleges and Universities, and practice environment factorization, to design talent training plan to meet the needs of cross border electricity providers with multi-level and multi positions. Through the practice in the author's university, it proved the effectiveness of the four principles of cross-border e-commerce talent cultivating program.
\end{abstract}

\section{跨境电子商务人才培养的“四化原则”与实践}

方美玉

浙江外国语学院跨境电子商务创业学院, 杭州, 中国

关键词：跨境电子商务; 人才培养; 人才模式设计; 实践

摘要：我国高校与跨境电子商务相关的国际贸易和电子商务专业很多，但是企业不到实践能 力强能适应岗位的大学生。这证明大学的跨境电商教育不被企业信任。本文分析了目前我国 高校跨境电商人才培养现状和问题所在。有针对性的提出了高校跨境电商人才培养方案设计 原理：“四化原则”。以“四化原则”即分层分段化、学科交叉复合化、校政企一体协同化、实 践环境工厂化为指导思想, 设计满足跨境电商多层次多岗位需求的人才培养方案。通过跨境 电商人才培养实践，证明了“四化原则”跨境电商人才培养方案的有效性。

\section{1. 我国高校跨境电商人才培养现状和问题}

目前, 在跨境电商领域, 毕业生主要来高职高专跨境电商专业和本科国际贸易、电子商 务、外语以及国际商务专业。全国高校中的国际贸易专业点有700多个，教育部批准的开设电 子商务本专科科学校1000多所。虽然开设国际贸易专业和电子商务专业的学校很多, 学生也 很多。但是, 跨境电子商务是一个复合型交叉性学科, 它具有国际贸易、国际商务和电子商 务专业的特点, 还需要英语或者多国语言背景。企业急需要复合型、有能力解决问题的人才。 据《中国跨境电商人才研究报告》调研结果分析, 大部分企业认为高校毕业生存在如下缺点: $81.9 \%$ 的企业认为毕业生解决问题的能力不强, $53 \%$ 的企业认为毕业生专业知识不扎实, 知识 面窄， $49.7 \%$ 的企业认为毕业生视野不够宽。 
已经有许多文献分别对跨境电商人才和高校人才培养体系等做了广泛而深入的研究。李 娜等高校人才培养方案设置角度, 以应用型本科院校为研究对象, 分别从课程体系、实践教 学、校政协同和加强与行业联系等方面提出了人才培养改革方式。王祥翠 (2013)以工商管理 大类专业为研究对象, 构建了“学科基础-专业学习-综合素质”三阶段人才培养模式。但是, 现 有研究还存在一些不足: 大部分研究是单纯从高校人才培养体系的三方面（师资队伍、课程 设置、实践教学) 的某一方面出发, 将各个实施环节全面结合起来研究的成果很少。专门分 析跨境电商创新创业人才培养方面的文献很稀缺, 结合跨境电商开展的研究也基本上参照了 其它专业创新创业人才培养模式。另外, 现有文献在高校、政府、企业三方联合培养研究方 面，大多只关注与政府、企业、行业协会之间的局部关系，很少见到从协同、制度创新等角 度深入剖析培养模式各个环节及其关系的研究成果。

\section{2. 基于 “四化原则” 的跨境电子商务人才培养模式设计}

“四化原则”指的是跨境电商人才培养方案设计“四化”。基于分层分段化的课程体系设计、 基于学科交叉复合化知识要求和素质要求设计、基于校政企一体协同化人才培养制度设计、 基于实践环境工厂化人才培养过程设计。其设计原理图如图 1。

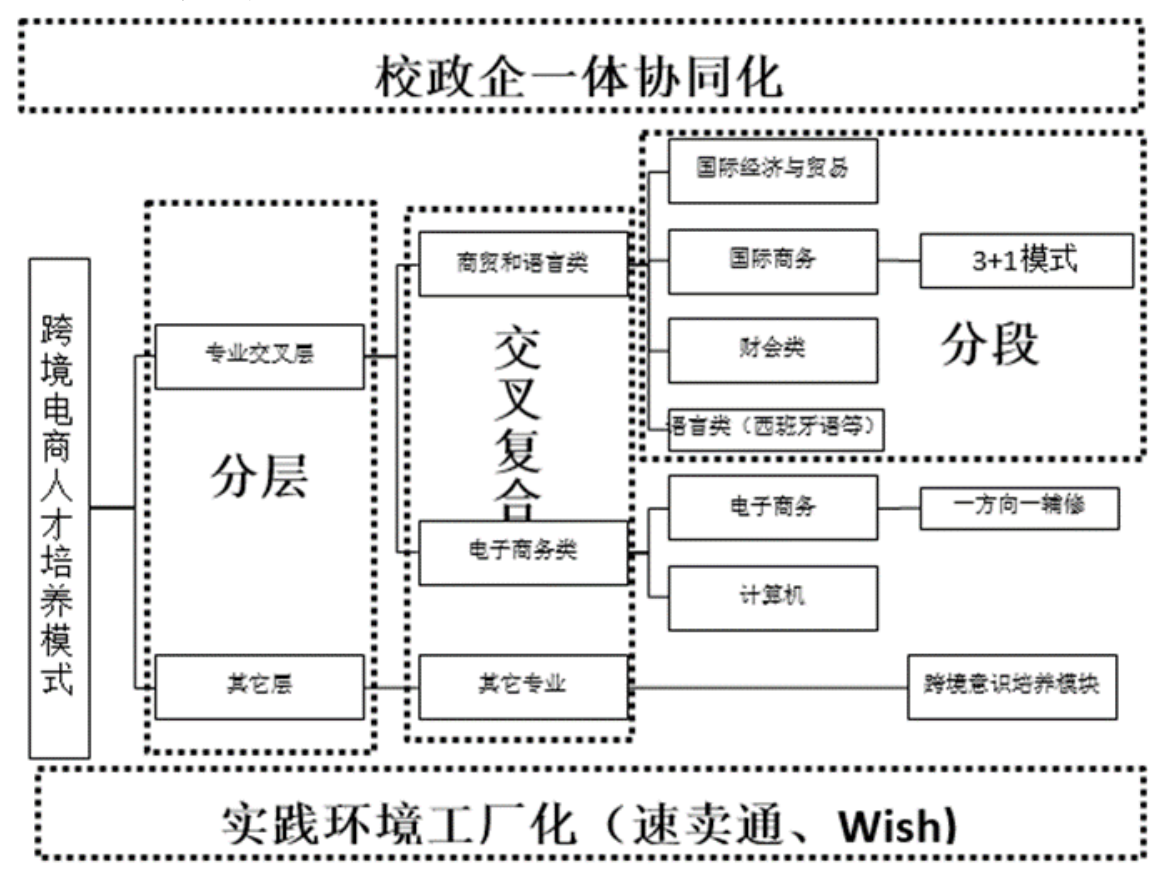

图 1 跨境电子商务人才培养的四化原则设计原理图

\section{1 基于分层分段化培养方案课程体系设计}

根据《中国跨境电商人才标准》的分类标准，跨境电商人才岗位有通用类、商务类、跨 境类三大类，总共有 60 多个岗位。对不同高校来说，一个本科专业的课程学分约 160 学分，其 中通识课与毕业实习、毕业论文等实践环节达到60学分左右, 专业课约60学分, 其课程数量 是有限的。一个专业方案不可能培养出三个大类几十个岗位都适合的人才, 所以在培养方案 设置的时候需要根据本校相关专业的实际情况进行分层, 需要确定本专业人才培养的岗位大 类。例如, 根据《中国跨境电商人才标准》分类标准和 2016 年《跨境电商产业紧缺人才需求 目录》岗位需求特点, 结合各高校实际, 大多数学校的语言类专业、国际经济与贸易、国际 商务、财会类、电子商务专业、计算机专业都可以适应商务类、跨境类所需求岗位的基本要 求。但是, 培养能够解决实际问题能力的跨境电商人才, 培养方案需要重点加强以下几方面 的能力培养：一是要求熟悉外贸规则及平台运营。跨境电商人才除了掌握传统的对外贸易规 则外，对于海关、海外仓储物流等跨境贸易新政策、新方式方法也要具备丰富实践经验。同 
时, 对多家国际知名的主流的交易平台要具备实践操作和运营能力。二是外语能力要求高。 由于贸易对象国家是多种语言不同国家, 跨境贸易销售衍生的一系列实践环节和经营过程中, 要求工作人员具备较强的外语口语及阅读、翻译及文档撰写能力。三是跨境电商人才比较重 视实际操作能力。跨境电商行业实操性强, 要求聘用人员能够直接上岗, 甚至能够独立操作 运营。

分层分段化指的是按照专业特点分层, 各层次专业结合原有课程体系分阶段设置培养目 标和课程体系。根据各专业与跨境电商的交叉程度, 跨境电商人才培养模式可以分类两个层 次: 专业交叉层和其它层。

专业交叉层的专业包括国际经济与贸易、国际商务、财会类、语言类、电子商务专业、 计算机专业类, 又可以归纳为两个子类: 经贸和语言类、电子商务类。经贸和语言类包括国 际经济与贸易、国际商务、财会类专业、语言类专业, 电子商务类包括电子商务专业、计算 机专业。专业交叉层的各专业可以通过改造培养体系来体现培养以上三方面的能力。

经贸和语言类培养体系改造分两个阶段进行，设置为“3+1”实验班模式。所谓“3+1”实验 班即经贸和语言类前期一到三年级为第一阶段, 本阶段为原专业模式, 本阶段的课程设置、 总学分都基本不变。第一阶段培养过程中侧重面稍加调整：经贸类专业需要强调学生的国际 化视野和英语口语、翻译能力; 语言类专业前三年开设国际商务方向课程（12-18学分），一 般结合综合语言课、翻译课开设国际商务礼仪、国际贸易、宏微观经济、会计学等课程; 四 年级阶段为第二阶段，本阶段改造为集中进行校政企三方合作的跨境电商教学模式。

电子商务类培养体系改造通过一方向一辅修循序推进模式进行。传统的电子商务或计算 机显然不能满足跨境电商的创业实践和小语种语言要求。根据国家教指委的要求, 电子商务 专业本身要求6门核心课程15 25学分 (电子商务概论、计算机编程、物流、营销、支付结算、 管理学等), 由于这一部分课程中不包含跨境电商理论与实践模块, 因此需要将跨境电商所 需要的关、检、汇、税、商、物、融、法等其它课程通过方向课的形式设置到培养体系中, 这 一部分方向课程需要学分数为 35 学分及以上。由此看来, 本专业已经学分充足。根据企业反 馈, 现阶段非常缺乏既要懂跨境电商又要懂小语种语言的电子商务人才, 在培养方案中设置 小语种语言课程很有必要。有条件的学校有小语种语言专业, 可以利用语言师资优势, 为电 子商务专业及计算机专业学生开设小语种语言课程。但是, 一般语言类课程都是需要一定的 学习周期和课时量才能达到基本听说能力。根据跨境电商企业提出的要求和语言类专家的建 议, 小语种语言比如西班牙语至少需要开设 38 学分以上才能具备基本的跨境客服所要求的素 质和能力。根据对语言类院校电子商务专业学生的调查发现, $74 \%$ 以上的学生有强烈意愿和 需求、 $25 \%$ 同学认为无所谓, 开了就学。只有不到 $1 \%$ 的同学反对。因此开设小语种语言虽然 增加学习负担, 但是却深受学生喜爱, 有很好的开设基础。因此以辅修专业或者第二专业形 式开设小语种辅修课, 既能很好的解决学分紧张、学生想学没地方学的矛盾、又能达到根据 市场需求，培养出具有跨境电商企业欢迎的人才。

其它层面专业由于专业特点与跨境电商能力需求较远，原则上培养目标不面向跨境电商 岗位人才, 一般采取跨境电商普及教育以培养跨境电商行业的前沿意识, 学校可以设置跨境 电商通识课模块（一般3-8学分），让感兴趣的学生选修。

\section{2 基于学科交叉复合化的知识要求和素质能力要求设计}

从跨境电子商务的概念来分析本质。跨境电子商务是指分属不同关境的交易主体，通过 电子商务平台达成交易、进行支付结算，并通过跨境物流送达商品、完成交易的一种国际商 业活动。因此, 跨境电子商务业务流程发生在互联网等计算机环境下, 涉及领域知识范围包 括关、检、汇、税、商、物、融、法八大领域、涉及的学科门类有五个: 工学、经济类、管理 学、文学、法学。涵盖六个专业领域: 计算机科学与技术、国际经济与贸易、国际商务、物流 管理、外国语言文学 (英语及其它小语种语言) 、知识产权。跨境电子商务学科交叉复合特 点明显, 人才培养方案设置首先需要综合化、复合化改革。 
基于跨境电商人才需求的复合型特点, 培养模式设计的知识要求关键要点需要涵盖掌握 经济、贸易、金融、管理、计算机等多方面的基本理论和方法; 熟练掌握英语, 在听、说、 读、写、译等方面均达到较高水平; 有条件需要辅修一门小语种语言, 并达到一定的读、写 水平。了解本学科领域的理论前沿及发展动态，具有较宽广的国际商贸文化视野。

基于跨境电商人才需求的学科交叉复合化因素，培养方案的素质要求应涵盖具有良好的 思想道德品质、较强的法制观念和诚信意识、知识产权意识以外; 有较高的人文、科学素养; 较强的团队合作意识和创业精神; 扎实的跨境商务活动能力等; 以及具有宽广的国际视野和 良好的跨文化沟通能力。

\section{3 基于校政企一体协同化人才培养制度设计}

“我们的人才没有跟上，不是一般的没有跟上，完全的脱轨”。之所以企业不信任高校，连 人才培训也不选择高校, 很大一部分原因是目前的高校与政府、企业互动很少。甚至有些老 师自娱自乐照本宣科, 很少关心政府的决策、知识体系更新严重滞后。社会需求变化很快, 而讲台上的老师却不动声色。当然也不只是因为老师们漠不关心、没有学习积极性。校政企 一体化协同很重要、政府的政策支持、经费支持、学校的勇于创新精神、服务地方经济的制 度设计思路、对教师考核与晋升制度改革力度、师资培养的方向等等, 都对教师的知识体系 更新和教学上能否与社会同步起着关键作用。

跨境电商是新兴行业，政府层面出台了许多保障型措施。杭政函〔2016)188号关于人才 培养的鼓励政策有：鼓励在杭高校结合产业发展实际需求开设跨境电子商务专业。对经教育 部批准开设跨境电子商务专业, 给予最高不超过 100 万元的一次性资金扶持; 鼓励跨境电子商 务企业引进跨境电子商务专业人才。符合“杭州市人才新政 27 条”相关条件的高端跨境电子商 务人才，可优先享受相关政策。

学校从组织机构方面重视, 设立健全的保障跨境电商创业及实践的组织机构。跨境电商 知识体系的交叉复合、实践性强等特点, 需要高校在人才培养方面打破学科壁垒, 支持多学 科之间跨学院融合。需要建立由学校一把手校长或者党委书记、分管教学、财务的主要领导、 学生处、教务处、校团委、二级学院专业负责人组成领导小组。同时明确领导小组职责为: 落实国家、浙江省及省教育主管部门文件精神和要求; 讨论决定校跨境电子商务创业学院重 大事项。我校率先成立以国际商务、计算机、金融工程等专业为基础的实体性质的跨境电商 学院。在跨境电商创业方面打破常规体制, 专门出台了各项规章制度, 以促进跨境电商创业 实践和学院的良好运行。在人才培养方案打破常规开绿灯，专门定制“3+1”实验班学分转换 教学及管理工作业绩点计算、“ $3+1$ ”实验班顶岗实习 (实训) 实施方案、“ “ $3+1$ ”实验班学生实 习 (实训) 工作流程等制度和文件。这些制度的建成, 为学院和跨境电商人才培养奠定了良 好基础。

主流的跨境电商平台上有成千上万家跨境电商卖家人才需求紧缺。要培养熟知主流跨境 电商平台规则、外贸规则, 熟练掌握海关、海外仓储物流等操作规程、具备跨境贸易国际交 易平台运营能力。跨境出口B2C主流平台有速卖通、亚马逊、Wish、Ebay等多家平台, 学校 需要在政府的支持下, 与主流平台联动, 将企业导师请进课堂来。

\section{4 基于实践环境工厂化人才培养过程设计}

跨境电商人才培养不同于其他单一学科, 其实践性和解决问题的能力培养是模拟实验环 境无法创造出来的。不能空谈模拟教学, 需要实施校企合作、产学研融合的工厂化人才培养 过程。

第一阶段为校内理论课，一般为一个半月课程。采取“双导师”“学分制“和”请进来“、”送 出去”的培养方式, 将学校理论导师的课程与企业导师的课程完全融合。培养方案的理论部分 由学校导师和企业导师共同完成，每门课一位责任教师，负责协调校企导师课程内容。一般 上校内导师讲授理论和不需要企业数据部分的内容、企业导师负责讲授企业数据分析与实操 
部分内容。全部课程的实践环境均由企业提供官方平台环境。比如: 在B2C跨境电商教学中, 对于需要企业才能注册的平台, 校内导师使用官方平台教学账号如速卖通教学账号、企业导 师直接使用卖家运营账号。对于个人可以注册账号的平台环境如Wish平台, 教师和学生要求 全部开设卖家账号, 学习的过程等同于创业过程。实施完全的工厂化实践环境, 学习过程可 以暴露出许多模拟账号无法凸显的问题, 解决问题的过程就是一种很好的学习方式, 走上企 业岗位才能够解决实际问题。

第二阶段为全球双十一实训周或者全球星期五购物节实训周（2周时间），将学生安排到 合作基地进行基础岗位锻炼。初步接触企业跨境电商工作环境, 熟悉工作流程, 增强岗位认 识。

第三阶段是毕业实习，为期一学期。联合实习合作单位和卖家企业实施双选，企业提供 岗位、学生选择岗位参加面试, 匹配成功上岗工作。这段时间完全成为企业一名员工, 可以 参加企业接受学徒制培养和轮岗训练。

\section{3. 我校的基于 “四化原则” 的跨境电商人才培养模式实践}

\section{1 我校跨境电商人才培养模式: $3+1$ 实验班和四年制本科班}

2016年3月, 浙江外国语学院以二级学院科学技术学院为依托, 以电子商务专业建设为契 机, 成立浙江省首个跨境电子商务创业学院。2016年学校批准了“3+1”实验班跨境人才培养模 式, 在学校已有小语种等各专业的基础上, 招收来自于全校7各学院 13 个不同专业包括外贸及 语言类专业44位学生, 迅速响应市场需求。截止2017年6月, 第一批复合型跨境电商人才出炉, 颇受企业欢迎。

在培养方案上设置了校企合作双导师、学分制授课，最终确定开设“跨境物流与国际支付、 跨境电商数据化管理、跨境电商营销、跨境电商美工、跨境电商平台实务、跨境客户服务、 创新创业基础”等课程。与企业导师共同确定了教材选用方案、每门课教学内容、课程责任教 师和备用教师; 定期督查和汇报备课进度, 讨论各门课程存在的问题; 确定了与企业深入合 作请进来教学方案。

第二种模式是电子商务本科跨境电商人才培养模式。以学校大环境 “三足”稳定结构为基 底, 集全校资力, 以信息技术为依托、侧重于经管应用、彰显跨文化交流特色的跨境电子商 务。首先在课程设置 (总学分 160 学分), 上凸显经管、外贸优势课程模块 (40\%专业课学 分）。第二，开设主要的电子商务运营和管理为主的 IT 技术课程（35\%的学分）; 第三，为 了解决专业学分紧张的情况, 在语言上采用辅修的形式, 要求学生大二开始选择一门小语种 辅修专业, (俄语、西班牙语、葡萄牙语、阿拉伯语和意大利语、法语, 选择一到两种专门开 班辅修）。第四, 开设实训、毕业实习定岗实习课程, 真正走进企业, 形成具有浙外文化软 实力特色的培养模式。本科生的跨境电商实践重点是跨境 $\mathrm{B} 2 \mathrm{~B}$ 模式的实践。三年级嵌入式 实践周和暑期实践安排 B2B 模式运营与实训课程, 解决企业需求与高校对接最后一公里问题。

\section{2 拓展校企政多方合作, 加强实验室建设, 夯实实践教学}

校企合作是跨境电商人才培养重要一环, 学院成立以来, 与知名跨境电商平台进行深入 合作。深入推进与中国（杭州）跨境电子商务综合试验区、Alibaba等企业在跨境电商创新创 业人才培养上的深入对接, 积极拓展与Amazon、大龙网、中国制造网、敦煌网等跨境电商平 台以及创客社区的合作交流，充分引进政府、企业的优质资源。

“3+1”实验班实行“理论+实践”的培养模式，因此在授课过程中也采用“校内研究教师+企 业实战导师”相结合的学分制模式, 校内导师与校外导师的在课程上一对一对接, 深入探讨提 高, 共同完成课程教学。与知名跨境电商企业: 华立集团下属全资子公司华立创客社区、速 卖通大学、Wish、浙江执御等8家企业进行对接，与企业教师（华立创客社区及区内企业技术 总监与总经理）与校内教师课程对接会与课程研讨会。在学生“国际双十一”实训、暑期卖家 
实习等实践环节，速卖通卖家企业、Wish卖家企业等校外实习单位和企业为我校提供了实践 与实习基地。

为了营造良好的跨境电子商务创新创业人才培养环境, 学校在场地、资金、实验室项目 等方面给予大力支持, 以加强创业学院的硬件建设。建成了大学生创新创业实验中心创业实 验室、“e-cross”众创空间实验室、“商务大数据和电子商务安全”等配套实验室与创业实践环境, 这些实验室的建成，为跨境电商人才的培养提供了有力的保障与支撑。

\section{4. 结论}

分层分阶段中的“3+1”实验班模式能够较好的利用已有贸易类和语言类专业基础, 快速培 养出跨境电商创新创业人才。实践证明, 已经毕业的学生在杭州、上海、深圳各大企业发挥 了骨干作用。自主创业的学生也初露锋芒，2016年第一届约有20\%学生进入跨境电商行业自 主创业和 2017 年第二届已有人人开设了Wish店铺, 截止2017年12月, 业绩最好的一位学生已 经年盈利超400万人民币。我校因此被杭州跨境电子商务综合试验区联合阿里巴巴集团授予 “跨境电商人才培育基地”的荣誉称号，并在由杭州综试区主办的“潮起钱塘 . 全球跨境电商峰 会”中荣获跨境电子商务“人才培育奖”。同时, 我校的“高校跨境电子商务人才培养示范中心 项目”跨境电商人才的培养的模式与范本在全国高校推广。

\section{5. 致谢}

本文为 2017 年第一批产学合作协同育人项目: 教学内容和课程体系改革项目(No: 201701042022)的阶段性成果。

\section{References}

[1] Lu B, Wang H. Research on the Competitive Strategy of Cross-Border E-Commerce Comprehensive Pilot Area Based on the Spatial Competition [M]. Hindawi Publishing Corp. 2016:19.

[2] FAN Xin-mi. Innovative Entrepreneurial Education in the Context of Globalization of Higher Education [J]. JOURNAL OF HEBEI NORMAL UNIVERSITY/Educational Science Edition/. Vol. 17, No 3, May, 2015: 101-107.

[2] Zhang Xiamen. Contradiction between Supply and Demand of Cross-border E-commerce Talents and Its Solution CONTEMPORARY ECONOMIC MANAGEMENT [J]. Vol. 39, No 9, Sep, 2017: 68-72.

[3] GAO Zi-qing1, ZHANG Jin-ping. Mode Construction of Cultivating Cross-border Electronic Commerce Talents in Synergy Between University, Enterprise, Industry and Government [J]. Heilongjiang Researches on Higher Education. Serial No 277, No 5, 2017:146-148.

[4] Phillips N., Lawrence, T.B., \& Hardy, C. Discourse and Institutions [J]. Academy of Management Review, 2004, 29(4): 635 - 652.

[5] Hu Leifang, A summary of the training of entrepreneurial talents in cross-border E-commerce[J], E-BUSINESS JOURNAL, Feb,2017(026): 58-59, 